\title{
Effects of the addition of electrolyzed water to a footbath solution on digital dermatitis incidence
}

\begin{abstract}
Digital dermatitis (DD) can cause lameness and pain in dairy cows. The objective of this 11 week study, conducted at the University of Kentucky Coldstream Dairy Research Farm, was to test the effects of electrolyzed water, in a copper sulfate solution on DD. A split, plastic footbath was used to deliver two footbath solutions. The control solution, assigned to the left hooves of the cow, contained $79.5 \mathrm{~L}$ of water with $1.75 \mathrm{~kg}$ of copper sulfate, and $325 \mathrm{~mL}$ of acidifier. The treatment solution, assigned to the right hooves of the cows, contained the same solution as the control side with the addition of 7.5L of electrolyzed water. The footbath solutions were made Monday thru Friday before morning milkings. Cows walked through the footbath while exiting the milking parlor once a day. The solutions were dumped after the completion of morning milkings. Holstein cows ( $\mathrm{n}=77$ ) DD were scored biweekly in the milking parlor to determine active or inactive DD. Rear hooves were hosed off to remove debris before being evaluated. A headlamp was worn to provide clarity of hooves while scoring. The FREQ Procedure of SAS (SAS Institute, Inc., Cary, NC) was used for a chi-square analysis and a McNemar's test was used to compare the number of hooves with active $\mathrm{DD}$ to the number of hooves with non-active DD. No significant differences in DD between the control and treatment groups existed $(P>0.05)$; however, over the course of the study, both footbath solutions improved DD overall $(P<0.01)$. These results suggest that the addition of electrolyzed water in a footbath solution had no negative effect on DD.
\end{abstract}

Keywords: digital dermatitis, footbath, hoof health, copper sulfate

\author{
Volume 6 Issue I - 2017
}

\author{
HK Himmelmann, BW Jones, JM Bewley \\ Department of Animal and Food Sciences, University of \\ Kentucky, USA
}

Correspondence: Barbara Jones, Department of Animal and Food Sciences, University of Kentucky, Lexington, KY 40546, Phone 207749 2766, Email bwjones@tarleton.edu

Received: August 02, 2017 | Published: October 09, 2017

\section{Introduction}

Digital dermatitis (DD) is a pressing issue in the dairy industry. Digital dermatitis is an infection caused by a spirochete infection on the back of the hoof, between the claws. ${ }^{1}$ The bacteria known as Treponema spp. are believed to be the causative agent of DD. ${ }^{2}$ The infection is likely to cause inflammation, which is the foundation for skin damage, pain, discomfort, and lameness.

If not prevented or treated, DD can cause serious economic losses. ${ }^{1}$ A footbath offers a low maintenance, low labor solution to the prevention and treatment of many hoof diseases, including DD. ${ }^{3}$ On average, the cost per DD case is $\$ 132.96 .{ }^{4}$ Treating DD on an individual basis would be laborious and time consuming. Therefore, $59 \%$ of dairies housing more than 200 cows used footbaths to treat and prevent DD. ${ }^{5}$ As operations are becoming larger, footbaths are being used more often. Between 1996 and 2007, the percentage of dairies using footbaths increased from 13.6 to 20.3 respectively. ${ }^{6}$

Formalin and copper sulfate are common footbath solution ingredients. Formalin can require long periods of soaking time which is unfeasible on large farms. ${ }^{7}$ Copper sulfate is a widely-used footbath ingredient that has negative environmental effects. Copper's tightly bound bonds prevent it from being filtered past the top layer of soil, causing it to accumulate. ${ }^{3}$ This increase in copper in the top soil can lead to plant copper toxicity causing inadequate growth of the plant. ${ }^{3}$ Biodegradable products such as tea tree oil have been evaluated as footbath solution. ${ }^{8}$ These biodegradable products performed similarly to copper sulfate, however, economic factors influenced the permanence of the product. ${ }^{8}$ Electrolyzed water is a dilute solution of $\mathrm{NaCl}$ or $\mathrm{KCl}-\mathrm{MgCl}_{2}$ with a $\mathrm{pH}$ ranging from 2 to $3 .{ }^{9}$ Electrolyzed water's properties allow it to reduce bacterial growth by amplifying the bacteria's sensitivity to chlorine. ${ }^{9}$ The chlorine present in the electrolyzed water then destroys the bacterial membranes. ${ }^{9}$ Therefore, the objective of this study was to explore electrolyzed water as a possible footbath additive along with copper sulfate on the prevention of DD.

\section{Materials and methods}

This study was approved by the University of Kentucky Institutional Animal Care and Use Committee (IACUC protocol number: 20162361) and was conducted at the University of Kentucky Coldstream Dairy Research Farm from April 26, 2016 (baseline) to July 5, 2016 (end). Holstein cows $(n=77)$ were separated into two groups that were balanced by DIM and parity and were housed in a compost bedded pack barn. The dimensions of the whole barn were $46.3 \mathrm{~m}$ by $40.2 \mathrm{~m}$. Kiln dried sawdust was used in the pack which was stirred twice daily with a rototiller. Two high volume low speed fans were located over each pack. Rubber flooring covered the feed alley floor, which was scraped once daily. A TMR was delivered in the morning and afternoon to meet the lactating cow nutritional needs. Sprinklers and fans were placed over the feed bunk which used a feed line headlock system. The compost bedded pack barn was located 60.02 meters from the milking parlor.

Digital dermatitis was scored before the footbath was applied to establish a baseline for the study. Hooves were trimmed by a professional hoof trimmer every 6months before starting the study on March 7, 2016. The footbath was filled before morning milkings five times a week for eleven weeks. The footbath solutionwas disposed of after morning milkings because of the ineffectiveness of electrolyzed 
water after 6hours upon being exposed to organic material. The footbath was rinsed with water before each use to eliminate debris. A split, plastic footbath (Intra Bath; Diamond Hoof Care LTD. Diamond City, Alberta, Canada) with each side being $32.5 \mathrm{~cm}$ wide and $233 \mathrm{~cm}$ long was used to deliver two footbath solutions. The footbath was placed in the exit alley of the milking parlor. The control solution, assigned to the left hooves of the cow, contained $79.5 \mathrm{~L}$ of water with $1.75 \mathrm{~kg}$ of copper sulfate, and $325 \mathrm{~mL}$ of acidifier. The treatment solution, assigned to the right hooves of the cows, contained the same solution as the control side with the addition of $7.5 \mathrm{~L}$ of electrolyzed water. The electrolyzed water was produced from a single stream electrolyzed water generator.

A five-point scoring system was used to classify the stages of DD for the rear hooves of each cow. These scores were assigned in the milking parlor. Scores ranged from M0 to M4 where M0 indicated no DD present, M1 indicated the beginnings of DD, M2 indicated active DD, M3 indicated scabbing or healing DD, and M4 indicated keratinized and protruding DD. ${ }^{10}$ To provide a clear view of each hoof for scoring, cow hooves were sprayed with water. A flashlight was used to visually evaluate the hooves.

The FREQ Procedure of SAS (SAS Institute, Inc., Cary, NC) was used to produce a chi-square analysis and a McNemar's test to analyze the deviations of DD from the beginning to end of the study. The FREQ procedure was also used to analyze the amount of DD at each scoring independently. The analysis compared the number of hooves with active DD (scores of M1 and M2) to the number of hooves with non-active DD (scores of M0, M3 and M4). The FREQ procedure analysis consisted only of cows that were present throughout the entire study. Cows that went dry, had missing data, or that were culled were excluded from all analyses.

\section{Results and dsiscussion}

No significant difference in DD existed between hooves with thecontrol or treatment solutions $(P \geq 0.05$; Table 1$)$. These results suggest that electrolyzed water had no negative effect on the effectiveness of a copper sulfate footbath solutions on DD. Zero cows developed new DD over the course of the study (Table 1). Sixty-seven hooves and sixty-four hooves began and ended the study with no DD present for control and treatment solutions, respectively (Table 1). These results provide evidence that routine footbath treatments are an effective way of preventing new DD.

Over time, both the control and treatment sides significantly improved the DD present and the overall number of active lesions decreased $(P \leq 0.01$; Table 1). Eight hooves from the control solution and twelve hooves from the treatment solution presented a lesion at the baseline of the study and presented no lesion at the end. This may be due to the cows moving to a composted bedded pack barn. The herd moved into this barn before the beginning of this study. The cows were previously housed in a free stall barn.

The number of non-active lesions decreased throughout the entirety of the study (Table 2). These hooves went from scores of M3 or M4 to scores of M0, or having no lesion present. Active lesions increased from 2 to 10 and 3 to 11 for the control side and treatment side, respectively (Table 3). Scores of M0, which indicated no DD, decreased and scores of M1, which indicated the beginnings of DD, increased (Table 4). However, no significant different between the treatments was found $(P \geq 0.05)$. The cause of this increase in active lesions may have been related to the excess manure in the barn. The alley is scraped only once per day. Scraping more than once per day reduces the incidence of clinical lameness cases. ${ }^{11}$

Table I Presence of active and inactive digital dermatitis at baseline and end ${ }^{1,2,3,4}$

\begin{tabular}{lll}
\hline Item & Control & Treatment \\
\hline No lesion at Baseline and no lesion at End & 67 & 64 \\
No lesion at Baseline and lesion at End & 0 & 0 \\
Lesion at Baseline and no lesion at End & 8 & 12 \\
Lesion at Baseline and lesion at End & 2 & 1 \\
\hline
\end{tabular}

'The baseline of the study was April 26, 2016 and the end was July 5, 2016

${ }^{2} \mathrm{~A}$ McNemars Test for control was used to produce these results

${ }^{3}$ The scoring system used consisted of five different scores. The scores ranged from $M 0$ to $M 4$ where $M 0$ indicated no DD present, $M I$ indicated the beginnings of $D D, M 2$ indicated active DD, $M 3$ indicated the scabbing or healing DD, and M4 indicated keratinized and protruding $D D^{10}$

${ }^{4} \mathrm{~A}$ split footbath was used for the treatment and prevention of DD. The solutions were a control side, assigned to the left legs of the cow, which consisted of $79.5 \mathrm{~L}$ of water with $1.75 \mathrm{~kg}$ of copper sulfate, and $325 \mathrm{~mL}$ of acidifier. The treatment side, assigned to the right legs of the cows, contained the same solution as the control side $(79.5 \mathrm{~L}$ of water with $1.75 \mathrm{~kg}$ of copper sulfate, and $325 \mathrm{~mL}$ of acidifier) with the addition of $10 \%$ (7.5liters) of electrolyzed water

Table 2 Raw frequency for non-active digital dermatitis at baseline and end fl, $2,3,4^{-}$

\begin{tabular}{lll}
\hline Scoring & $\begin{array}{l}\text { Control [no. (\% of Hooves } \\
\text { with digital dermatitis)] }\end{array}$ & $\begin{array}{l}\text { Treatment [no. (\% of } \\
\text { Hooves with digital } \\
\text { dermatitis)] }\end{array}$ \\
\hline Baseline & $75(26.6)$ & $74(26.24)$ \\
End & $67(23.76)$ & $66(23.40)$
\end{tabular}

'The baseline of the study was April 26, 2016 and the end was July 5, 2016

${ }^{2}$ TheFREQ Procedure was used to produce these results

${ }^{3}$ The scoring system used consisted of five different scores. The scores ranged from M0 to M4 where M0 indicated no DD present, MI indicated the beginnings of DD, M2 indicated active DD, M3 indicated the scabbing or healing DD, and $M 4$ indicated keratinized and protruding DD. ${ }^{10} \mathrm{~A}$ score of $\mathrm{M0}, \mathrm{M} 3$, or $\mathrm{M} 4$ are considered inactive lesions. A score of $\mathrm{MI}$ or $\mathrm{M} 2$ are considered active lesions ${ }^{10}$

${ }^{4} \mathrm{~A}$ split footbath was used for the treatment and prevention of DD. The solutions were a control side, assigned to the left legs of the cow, which consisted of $79.5 \mathrm{~L}$ of water with $1.75 \mathrm{~kg}$ of copper sulfate, and $325 \mathrm{~mL}$ of acidifier. The treatment side, assigned to the right legs of the cows, contained the same solution as the control side $(79.5 \mathrm{~L}$ of water with $1.75 \mathrm{~kg}$ of copper sulfate, and $325 \mathrm{~mL}$ of acidifier) with the addition of $10 \%$ (7.5liters) of electrolyzed water

No significant difference in DD incidence between the control and treatment groups shows that electrolyzed water had no negative effect on DD. Thus, electrolyzed water is a safe footbath additive. Copper sulfate has negative environmental effects including soil toxicity. ${ }^{3}$ Electrolyzed water has no negative effects on the environment. ${ }^{9}$ After use, electrolyzed water reverts back to its original state of regular water. ${ }^{9}$ Using electrolyzed water in footbath solutions is an environmentally safe way to ensure antimicrobial activity. 
Table 3 Raw frequency for active digital dermatitis at baseline and end ${ }^{1,2,3,4}$

\begin{tabular}{lll}
\hline Scoring & $\begin{array}{l}\text { Control [no. (\% of hooves } \\
\text { with digital dermatitis)] }\end{array}$ & $\begin{array}{l}\text { Treatment [no. (\% of } \\
\text { hooves with digital } \\
\text { dermatitis)] }\end{array}$ \\
\hline Baseline & $2(7.69)$ & $3(1 \mathrm{I} .54)$ \\
End & $10(38.46)$ & $\mathrm{II}(42.3 \mathrm{I})$
\end{tabular}

'The baseline of the study was April 26, 2016 and the end was July 5, 2016

${ }^{2}$ The FREQ Procedure was used to produce these results

${ }^{3}$ The scoring system used consisted of five different scores. The scores ranged from M0 to M4 where scores $\mathrm{MI}$ and $\mathrm{M} 2$ represented active DD. ${ }^{10}$

${ }^{4} \mathrm{~A}$ split footbath was used for the treatment and prevention of DD. The solutions were a control side, assigned to the left legs of the cow, which consisted of $79.5 \mathrm{~L}$ of water with $1.75 \mathrm{~kg}$ of copper sulfate, and $325 \mathrm{~mL}$ of acidifier. The treatment side, assigned to the right legs of the cows, contained the same solution as the control side $(79.5 \mathrm{~L}$ of water with $1.75 \mathrm{~kg}$ of copper sulfate, and $325 \mathrm{~mL}$ of acidifier) with the addition of $10 \%$ (7.5 liters) of electrolyzed water

Table 4 Raw frequency of severity of total (hooves) digital dermatitis from baseline to end $d^{1,2,3,4}$

\begin{tabular}{llllll}
\hline Scoring & M0 & MI & M2 & M3 & M4 \\
\hline Baseline & 22 & 5 & 0 & 123 & 4 \\
End & 10 & 19 & 2 & 123 & 0
\end{tabular}

'The baseline of the study was April 26, 2016 and the end was July 5, 2016

${ }^{2}$ The FREQ Procedure was used to produce these results

${ }^{3}$ The scoring system used consisted of five different scores. The scores ranged from $M 0$ to $M 4$ where $M 0$ indicated no DD present, $M I$ indicated the beginnings of DD, $M 2$ indicated active DD, $M 3$ indicated the scabbing or healing DD, and M4 indicated keratinized and protruding $D^{10}$

${ }^{4} \mathrm{~A}$ split footbath was used for the treatment and prevention of DD. The solutions were a control side, assigned to the left legs of the cow, which consisted of $79.5 \mathrm{~L}$ of water with $1.75 \mathrm{~kg}$ of copper sulfate, and $325 \mathrm{~mL}$ of acidifier. The treatment side, assigned to the right legs of the cows, contained the same solution as the control side $(79.5 \mathrm{~L}$ of water with $1.75 \mathrm{~kg}$ of copper sulfate, and $325 \mathrm{~mL}$ of acidifier) with the addition of $10 \%$ (7.5liters) of electrolyzed water

\section{Conclusion}

The objective of this study was to test for negative effects of electrolyzed water in a footbath solution. No significant difference in DD incidence existed between the control and treatment solutions. Therefore, electrolyzed water had no negative effects on the prevalence of DD. These results suggest that electrolyzed water footbaths perform well in footbath solutions.

\section{Acknowledgements}

The authors would like to thank JoeyClark, Amelia Fendley, Brittany Core and the staff at the University of Kentucky Coldstream Dairy Research Farm, for their support in this project. The authors would also like to thank GEA for their financial support.

\section{Conflict of interest}

The research of this study remained unbiased throughout the entity of the study. The faculty, staff, and researchers reported all data honestly as it was collected.

\section{References}

1. Palmer MA, O'Connell NE. Digital Dermatitis in Dairy Cows: A Review of Risk Factors and Potential Sources of Between-Animal Variation in Susceptibility. Animals. 2015;5(3):512-535.

2. Krull AC, Shearer JK, Patrick JG, et al. Bacterial Causes of Kigital Kermatitis (DD) in Dairy Cattle. Ames, Iowa: Animal Industry Report, Iowa State University; 2015:1-6 p.

3. Downing TW, Stiglbauer K, Gamroth MJ, et al. CASE STUDY: Use of Copper Sulfate and Zinc Sulfate in Footbaths on Oregon Dairies. The Professional Animal Scientist. 2010;26(3):332-334.

4. Cha E, Hertl JA, Bar D, et al. The cost of different types of lameness in dairy cows calculated by dynamic programming. Prev Vet Med. 2010;97(1):1-8.

5. Cook NB. Prevalence of lameness among dairy cattle in Wisconsin as a function of housing type and stall surface. J Am Vet Med Assoc. 2003;223(9):1324-1328.

6. Part V: Changes in Dairy Cattle Health and Management Practices in the United States, 1996-2007. USDA: APHIS: VS, CEAH, National Animal Health Monitoring Systems: Fort Collins. USA; 2007.

7. Teixeira AG, Machado VS, Caixeta LS, et al. Efficacy of formalin, copper sulfate, and a commercial footbath product in the control of digital dermatitis. J Dairy Sci. 2010;93(8):3628-3634.

8. Smith AC, Wood CL, McQuerry KJ, et al. Effect of a tea tree oil and organic acid footbath solution on digital dermatitis in dairy cows. J Dairy Sci. 2014;97(4):2498-2501.

9. Huang YR, Hung YC, Shun YH, et al. Application of electrolyzed water in the food industry. Food Control. 2008;19(4):329-345.

10. Döpfer D, Koopmans A, Meijer FA, et al. Histological and bacteriological evaluation of digital dermatitis in cattle, with special reference to spirochaetes and Campylobacter faecalis. Vet Rec. 1997;140(24):620-623.

11. King MT, Pajor EA, LeBlanc SJ, et al. Associations of herd-level housing, management, and lameness prevalence with productivity and cow behavior in herds with automated milking systems. J Dairy Sci. 2016;99(11):9069-9079. 